\title{
HIP MODELING OF SUPERALLOY POWDERS
}

\author{
J.C. Borofka*, R.D. Kissinger**, and J.K. Tien* \\ *Columbia University, Henry Krumb School of Mines \\ Center for Strategic Materials \\ 500 West 120th Street, 1124A S.W. Mudd Building \\ New York City, New York 10027-6699 \\ **General Electric Company \\ Engineering Materials Technology Laboratories \\ 1 Neumann Way, Box 156301, Mail Drop M85
}

Cincinnatti, Ohio 45215-6301

\begin{abstract}
Modeling of Hot Isostatic Pressing (HIP) allows for the prediction and optimization of densification kinetics and mechanisms. Monosized and bimodal powder distributions have been modeled. The results are best presented on HIP maps which show regimes of dominance for each mechanism in terms of HIP pressure versus density. In this work, the bimodal HIP model is extended to include kinetics of densification and both models are extended to consider densification by superplastic deformation. Kinetics from these two models are compared to experimental HIP densification data for René 95. Agreement between the models and experimental data is good. Through the use of HIP mechanism maps and with a detailed understanding of HIP kinetics, HIP cycles can be designed to control the dominant densification mechanism. Ramped pressure HIP runs were done in an effort to improve the as-HIP microstructure of René 95 powder, with promising results. The models can also be applied to other processing techniques as well as to HIP of new material systems and composites.
\end{abstract}




\section{Introduction}

Previously, the mechanisms and kinetics of HIP have been modeled for a single average powder particle radius $(1,2)$ using the mechanisms of yield, power law creep, diffusional creep and diffusion. In a monosized powder distribution, the instantaneous stresses on all particles (at a given value of density) during HIP are the same and the deformation which leads to densification is uniform for all particles.

However, in a commercial distribution of powder (be it superalloy or any other material) a full spectrum of powder particle sizes is present. This leads to a non-uniform distribution of stresses and therefore non-uniform deformation of powder particles during HIP consolidation. Figure 1 shows an as-HIP superalloy, heat-treated to delineate the prior particle boundaries. The smaller particles have deformed to a greater extent than the large particles, in fact many large particles do not appear to have deformed at all, and have left behind smooth spherical (circular in cross-section) shells or crusts of surface segregation and/or contamination (3) in the densified material. These shells are known as prior particle boundaries (or $\mathrm{ppb}$ ) and can degrade mechanical properties $(4,5)$ by acting as easy propagation paths for fatigue cracks or by acting as low cycle fatigue initiation sites at extended reactive defects (6). Careful policing of the $P / M$ process, which includes powder screening and container filling, improves the ppb problem in the as-HIP material, however some segregation or coarsening at the particle surfaces will remain. The stress and morphology differences that occur during HIP of commercial powder cannot be addressed by a model which only considers a monosized distribution of powder.

In order to more closely model reality, HIP of a bimodal distribution of powder sizes has been modeled $(7,8,9)$. This model allows examination of the stress differences among powder particles, and can be applied to other material processing problems. In this paper, the monosized and bimodal HIP models have been extended to include densification by superplasticity, and densification kinetics have been added to the bimodal model. Experimental HIP data is compared to predicted results, and methods to improve the microstructure and properties of as-HIP superalloy are discussed.

\section{HIP Modeling}

The HIP models follow the technique used by Arzt et al. (1). Densification is modeled as the fictitious growth of spheres, which is mathematically equivalent to the movement of spheres closer together because volume is conserved over the powder bulk. The powder particles are considered to be spheres of radius $R_{1}$ and $R_{2}$ ( $R_{1}<R_{2}$, where $R_{1}=R_{2}$ for monosized powder) present in weight fractions $w_{1}$ and $w_{2}$ (which can be related to $v_{i}$ and $n_{i}$, volume and number fractions, respectively: $\left.\mathrm{v}_{\mathrm{i}}=\mathrm{w}_{\mathrm{i}} \mathrm{D}_{\mathrm{o}}, \mathrm{n}_{\mathrm{i}}=\left(\mathrm{w}_{\mathrm{i}} / \mathrm{R}_{\mathrm{i}}\right) / \Sigma\left(\mathrm{w}_{\mathrm{i}} / \mathrm{R}_{\mathrm{i}}\right)\right)$. The density is related to the change in radius (7):

$$
\mathrm{D} / \mathrm{D}_{\mathrm{o}}=\sum_{\mathrm{i}} \mathrm{v}_{\mathrm{i}}\left(\mathrm{R}_{\mathrm{i}} / \mathrm{R}_{\mathrm{oi}}\right)^{3}
$$

where $D$ and $D_{0}$ are the current and initial relative density respectively, and $R_{i}$ and $R_{o i}$ are the current and initial radius of particle $i$, where $i$ takes the values 1 and 2 for the bimodal case. For the monosized case, no subscripts and sums are necessary, since all values are the same.

\section{Contact Stresses}

As densification proceeds and the spheres "grow", they approach one another and "overlap", as shown schematically in Figure 2. The overlap volume is mathematically distributed evenly over the exposed surface area of the spheres, 


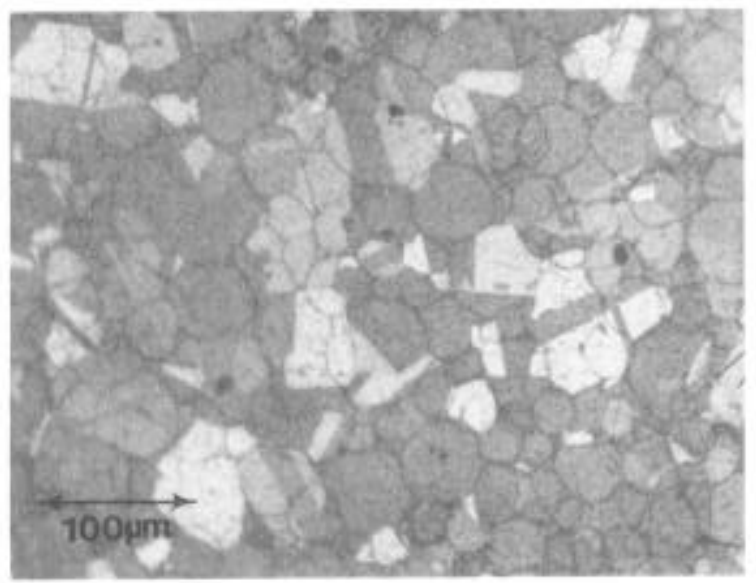

Figure 1. As-HIP René 95 (commercial powder distribution), heattreated to emphasize prior particle boundary (ppb) morphology. The smaller particles in the distribution have suffered more deformation than the large particles.

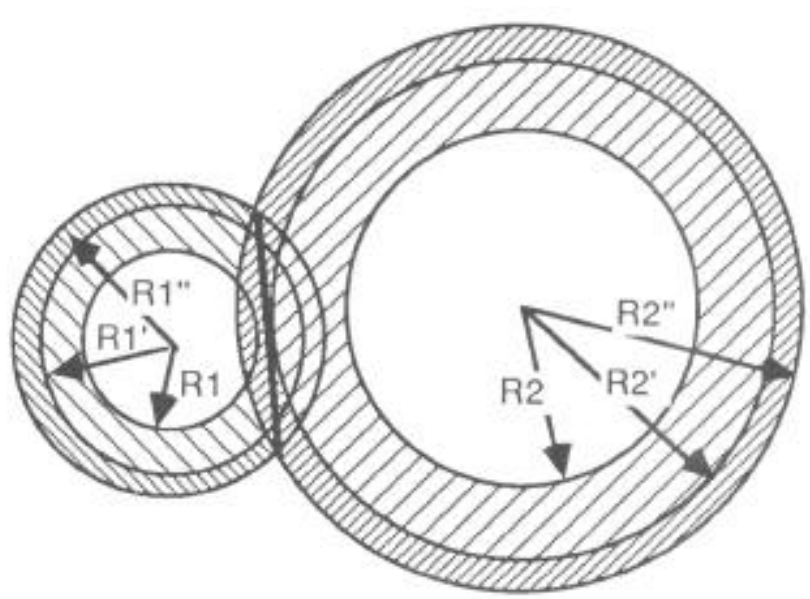

Figure 2. The "growth" (coarse hatching) of powder particles leads to "overlap" volume (dark shading) which is distributed evenly over the exposed surface area (fine hatching). This leads to further overlap, and so on. The neck radius $x_{i j}$ and density are calculated when $R_{i}$ " becomes invariant for each "growth step".

which in turn leads to a further increase in the radius and overlap volume, and so on. As the particles contact, they form necks of area $a_{i j}$. The contact stress (effective pressure) $\mathrm{P}_{\mathrm{ij}}{ }^{*}$ due to the applied HIP pressure $\mathrm{P}_{\mathrm{HIP}}$ on these contacts can be calculated (7):

$$
P_{i j}^{*}=\left(1 / a_{i j}\right)\left(\pi P_{H I P} / \quad \sum_{i} v_{i} \sum_{j} N_{i j} / R_{i}^{2}\right)
$$

where $\mathrm{N}_{\mathrm{ij}}$ is the number of $\mathrm{j}$ particles around an i particle, which is calculated from the radial distribution functions of a bimodal distribution of powder (10). The subscripts $\mathrm{i}$ and $\mathrm{j}$ take the values 1 and 2 in this and the following equations.

As this growth and formation of contacts continues, the contact stresses drop, and finally no exposed surface area remains on the spheres. In this stage, the material consists of isolated pores, and individual spheres cannot be readily identified. This stage occurs at about $90 \%$ relative density for the monosized case and $80 \%$ for the bimodal case. The final stage of densification is modeled as the closure of a distribution of isolated pores. The contact stress is taken as equal to the HIP pressure (2):

$$
\mathrm{P}_{\mathrm{ij}}{ }^{*}=\mathrm{P}_{\text {HIP. }} \text {. }
$$

The powder size dependence of HIP is seen explicitly in the stress equation for the initial stage of HIP from the contact area. The contact areas for small particles are smaller and lead to higher contact stresses than are experienced by the larger particles. Another effect of smaller particle radii is to change the initial density of the powder - a finer distribution of powder will have a higher initial density.

\section{Densification Mechanisms and Densification Rates}

The contact stress is used as input for constitutive equations for. each mechanism under consideration and used to calculate a densification rate (D) for 
each mechanism. The rates are summed for all mechanisms (m) for each particle (i), then weighted by number fraction of each particle for a total densification rate:

$$
\dot{\mathrm{D}}=\sum_{\mathbf{i}} \mathrm{n}_{\mathbf{i}} \sum_{\mathrm{m}} \dot{\mathrm{D}}_{\mathrm{im}}
$$

Material parameters of René 95 , a typical and commercially important $P / M$ superalloy, are used as input for the modeling and are shown in Figures 3 and 4 and in the references $(8,13)$. The mechanical properties of the powder particles most likely varies with particle size, because the grain size and crystalline morphology of the powder particles vary with particle size (14). As powder diameter decreases, the microstructure of the powder particles changes from coarse polycrystalline, to fine polycrystalline, to monocrystalline or nearly glassy. However, in this paper, the microstructure and therefore mechanical properties of all powder particles are taken to be cqual.

Yielding. When the contact stress exceeds the yield strength of the powder particle material, yielding occurs at a very fast but finite rate, as with hot extrusion or hot forging. The yield strength of most materials is temperature dependent. However, the rate of yielding is not temperature dependent, which has lead in the past to the somewhat misleading labeling of this mechanism as athermal plastic flow. The temperature dependence of the yield strength of René 95 is shown in Figure 3. The densification rate for yielding is taken to be:

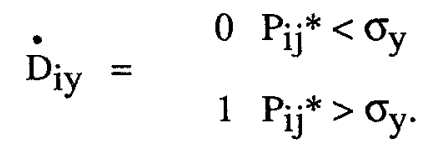

The particle size dependence affects the yield densification rate intrinsically through the effective stress on the particles, which is higher on the small particles.
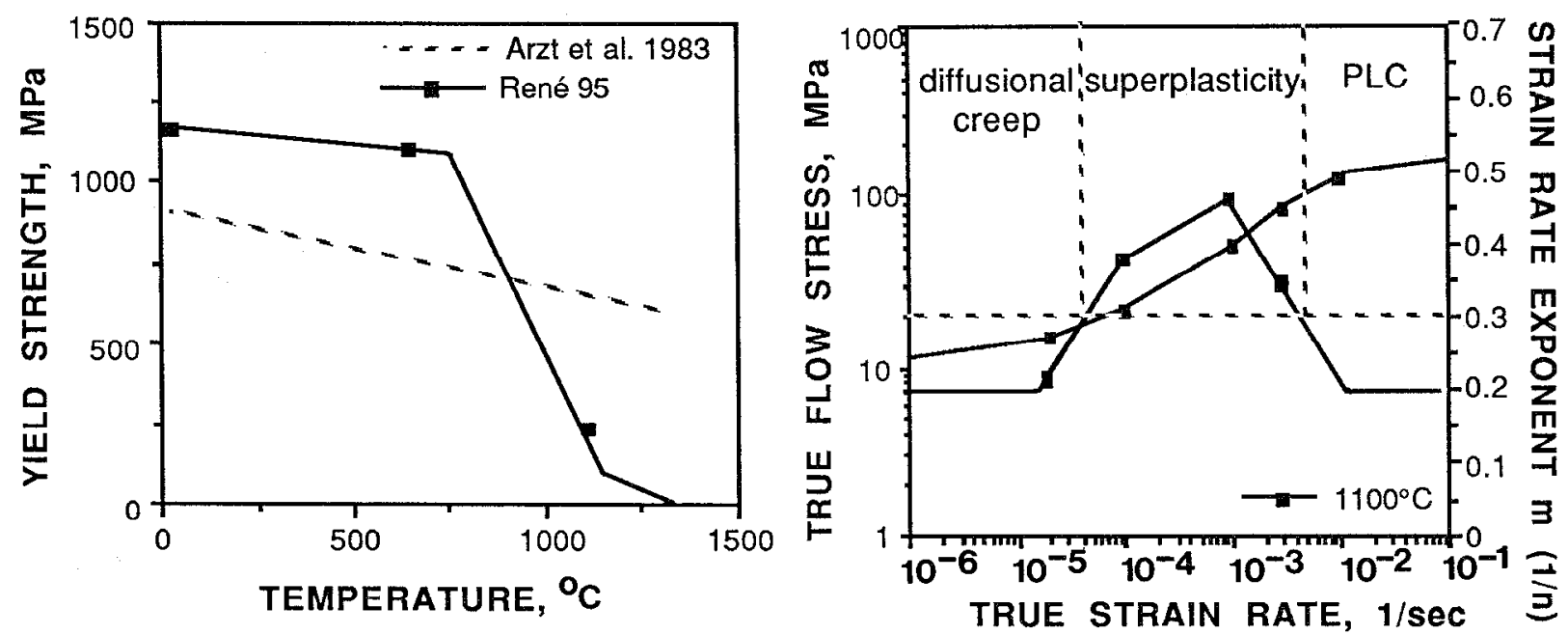

Figure 3. Temperature dependence of yield strength of superalloys at a strain rate of approximately $1.0 \mathrm{sec}^{-1}$. For this work, the data for René 95 is used $(11,12)$.

Figure 4. Flow stress-strain rate behavior of René 95 . Strain rate exponents greater than 0.3 are taken to be indicative of superplasticity, and are used to determine which mechanism operates at the associated stress. 
Power Law Creep and Superplasticity.

These two mechanisms are considered to act exclusively of one another. The creep behavior of René 95 is used to determine at which stresses each mechanism operates, see Figure 4 . The flow stress - strain rate behavior determines which mechanism operates at any particular stress through the usual criterion for superplasticity, that of a strain rate exponent $\mathrm{m}$ greater than 0.3 in the creep equation $\sigma=A \dot{\varepsilon}^{\mathrm{m}}$, where $\mathrm{m}=1 / \mathrm{n}$ and $\mathrm{n}$ is the power law creep stress exponent. The appropriate creep parameters $\left(\mathrm{n}, \dot{\varepsilon}_{0}, \sigma_{0}\right)$ for each regime are used in the densification rate equation $(1,8)$.

Diffusional Creep (Nabarro-Herring/Coble Creep). This densification mechanism which involves grain boundary sliding and diffusion only operates when the grain size of the powder is small compared to the powder size. The grain size of argon-atomized superalloy powder is typically below $10 \mu \mathrm{m}$. The densification rate is given elsewhere $(1,8)$.

Diffusion. Densification by long-range diffusion is similar to sintering, and is rather slow. The densification rate $(2,14)$ is strongly affected by particle radius. Smaller particles have smaller radii of curvature at the interparticle necks and diffusion densification is enhanced.

\section{HIP Maps}

The densification rate equations are evaluated at a constant HIP temperature for a range of HIP pressures. The mechanism with the greatest densification rate is considered to be dominant at that HIP pressure and density. The densification rates are summed up and integrated to predict densification kinetics. The data is presented on a HIP map or diagram that shows fields of dominance for cach mechanism in HIP pressure and density. Maps can also be created for a constant HIP pressure with a range of HIP temperatures. Figure 5 shows maps for distributions of powders with $R_{2}=R_{1}, R_{2}=2.3 R_{1}$ and $R_{2}=5.0 R_{1}$.

The HIP maps show fields of dominance for densification by yielding, power law creep, superplasticity, diffusional creep and diffusion. As is to be expected, at high HIP pressures, yielding dominates densification. At low HIP pressures, diffusional creep and diffusion dominate. Kinetics of densification will be discussed in the next section.

For the bimodal maps, each regime boundary has two values - one for the small particles and one for the large particles. As the difference in powder size increases, the split between the two values widens. For each mechanism, the boundary of the small particles is shifted upward compared to that of the large particles. This difference arises from the predicted and experimentally observed higher average stresses on the small particles. This difference means, for example at the yicld/power law creep boundary, that the small particles deform by the very rapid yield mechanism longer (to a higher density) than the large particles. This effect leads to the difference in degree of deformation of particles which contributes to the ppb problem.

A way to minimize the difference in deformation between particles is to maintain HIP densification by a single dominating mechanism, especially by a mechanism such as superplasticity which is well-known for the uniformity of deformation over varying areas or gauge lengths. If the HIP pressure is increased during the HIP run, the interparticle contact stresses can be kept constant, rather than falling as the interparticle contact areas increase. In this way, a particular mechanism (in this case, superplasticity) can be allowed to dominate for the entire duration of the run, as shown by the dotted line in Figure 5a. The dotted line represents a density-pressure path for $m=0.35$, which maximizes the degree of superplastic deformation experienced by the powder particles. If the HIP pressure is held constant during a HIP run, any given mechanism will dominate for only a small range of the densification process. 

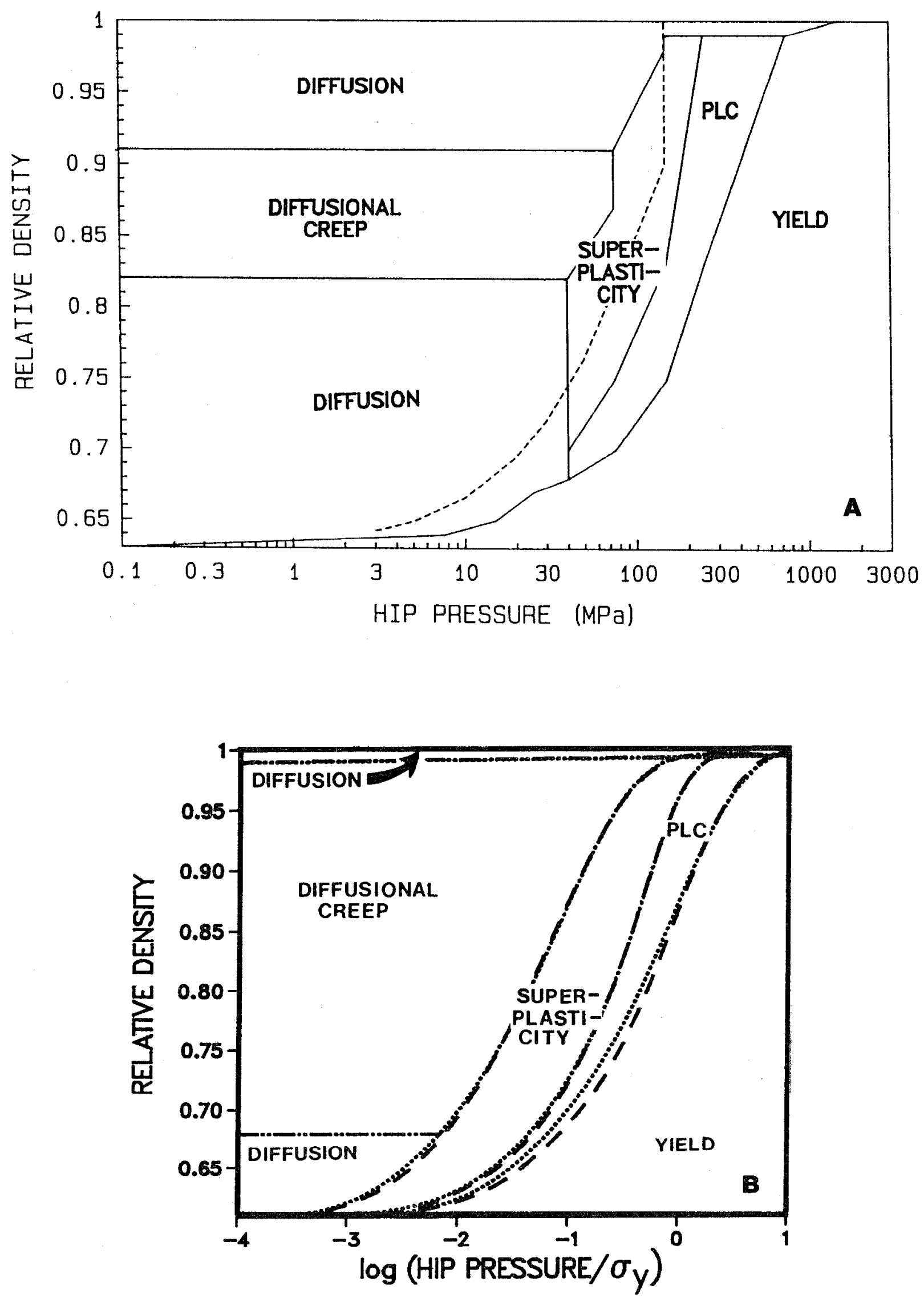

small particles

- - large particles 


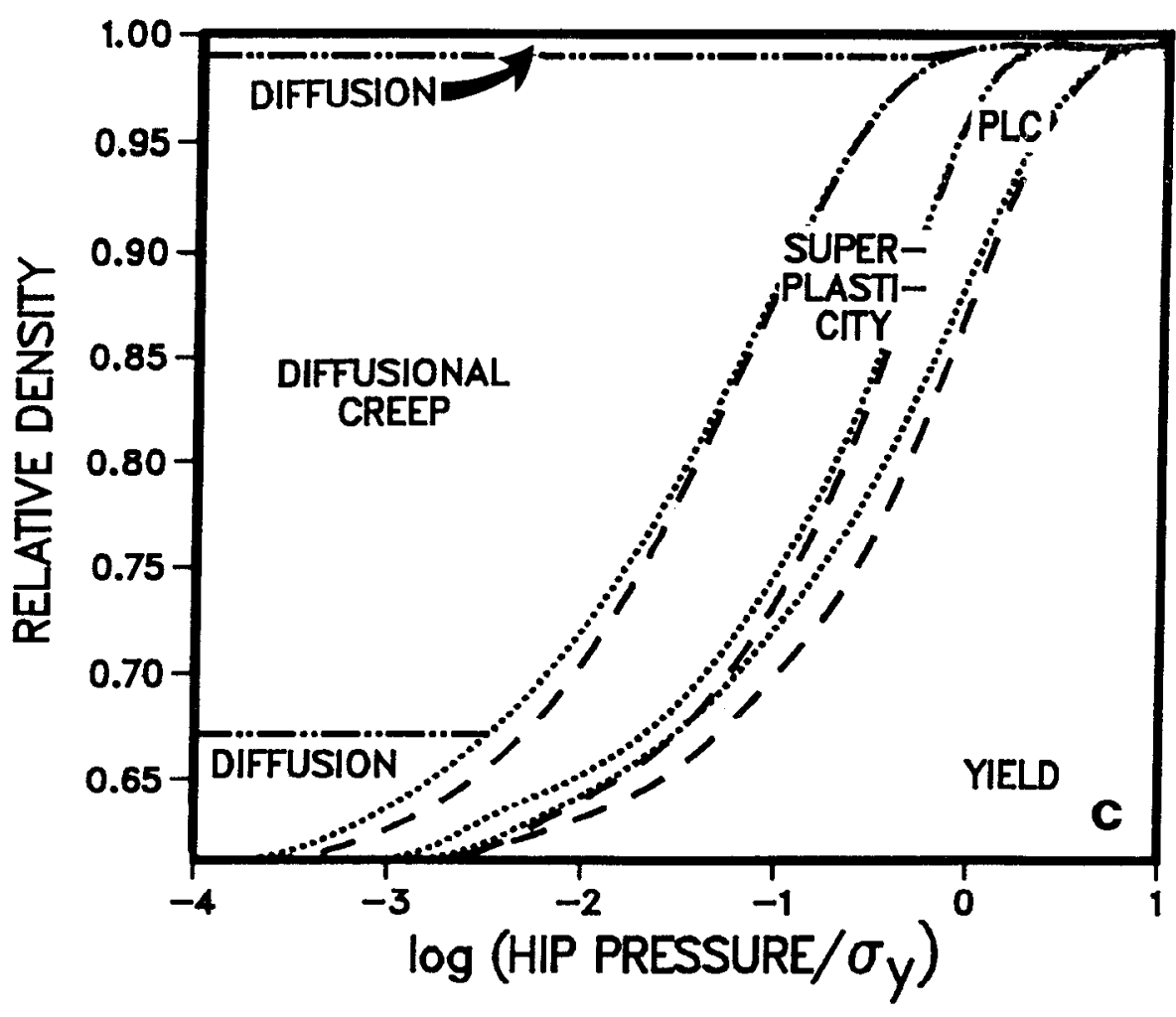

Figure 5. HIP maps for René 95 monosized and bimodal distributions (weight fractions of $10 \%$ and $90 \%$ for the small and large particles respectively). HIP temperature and $\mathrm{R}_{2} / \mathrm{R}_{1}$ are a) $1121^{\circ} \mathrm{C}$ and 1.0 , b) $1100^{\circ} \mathrm{C}$ and 2.3 , and c) $1100^{\circ} \mathrm{C}$ and 5.0. As the ratio of particle sizes increases, the split between the mechanism boundaries for the large and small particles increases. The dotted line in a) represents a density pressure path which maximizes superplasticity $(m=0.35)$.

\section{Experimental HIP Runs and Comparison to Modeling}

Argon-atomized René 95 powder was sieved and classified into various distributions, as shown in Table $I$. The powder was transferred to stainless steel cans (either $4 \mathrm{~cm}$ diameter $\times 10 \mathrm{~cm}$ height or $15 \mathrm{~cm} \times 18 \mathrm{~cm}$ ). All handling was done in an inert atmosphere, and all cans were outgassed. The HIP conditions and initial and final heatup-cooldown schedules used are shown in Table II. The densities of the as-HIP material were then measured using a water displacement technique.

A comparison of densities of HIP runs from Table II and predicted densification kinetics is shown in Figure 6. Note that the model can not only predict the increase in density occuring during the hold time at maximum temperature and pressure, but can also be used to predict the increase in density at the start and end of the HIP cycle. Agreement between the experimental data and predicted kinetics is good.

Table I. Powder Size Distributions

\begin{tabular}{|c|c|c|c|c|c|c|}
\hline Powder & & $\begin{array}{l}\text { Sieve } \\
\text { Size }\end{array}$ & $\begin{array}{l}\text { Average } \\
\text { Diameter, } \mu \mathrm{m}\end{array}$ & $\begin{array}{l}\mathrm{w}_{\mathrm{i}} \\
\%\end{array}$ & $\begin{array}{l}\mathrm{f}_{\mathrm{i}}, \\
\%\end{array}$ & $\begin{array}{l}\mathrm{n}_{\mathrm{i}} \text {, } \\
\%\end{array}$ \\
\hline Monosized (M) & & $-170+200$ & 81 & 100 & 100 & 100 \\
\hline Bimodal (B) & $\begin{array}{l}(\text { small }) \\
(\text { large })\end{array}$ & $\begin{array}{l}-400+500 \\
-170+200\end{array}$ & $\begin{array}{l}28 \\
81\end{array}$ & 10 & $\begin{array}{l}6 \\
55 \\
100\end{array}$ & $\begin{array}{l}24 \\
76\end{array}$ \\
\hline Full (F) & & -140 & 19.5 & & & \\
\hline
\end{tabular}


Table II. Experimental HIP Conditions.

\begin{tabular}{|c|c|c|c|c|c|}
\hline $\begin{array}{l}\text { HIP } \\
\mathrm{T},{ }^{\circ} \mathrm{C}\end{array}$ & Powder & $\begin{array}{l}\text { HIP P, } \\
\text { MPa }\end{array}$ & $\begin{array}{l}\text { Pressure Up \& } \\
\text { Heatup, min }\end{array}$ & $\begin{array}{l}\text { Hold Time, } \\
\text { m in }\end{array}$ & $\begin{array}{l}\text { Pressure Down \& } \\
\text { Cooldown, min }\end{array}$ \\
\hline 900 & B & 103.0 & 60 & $5,15,60,180$ & 60 \\
\hline 1000 & $\mathrm{M}, \mathrm{B}, \mathrm{F}$ & 10.3 & 60 & $5,15,60,180$ & 60 \\
\hline 1121 & $\mathrm{M}, \mathrm{B}, \mathrm{F}$ & 103.0 & 60 & 5 & 60 \\
\hline 1121 & $F$ & 10.3 & 60 & $5,15,60$ & 60 \\
\hline
\end{tabular}
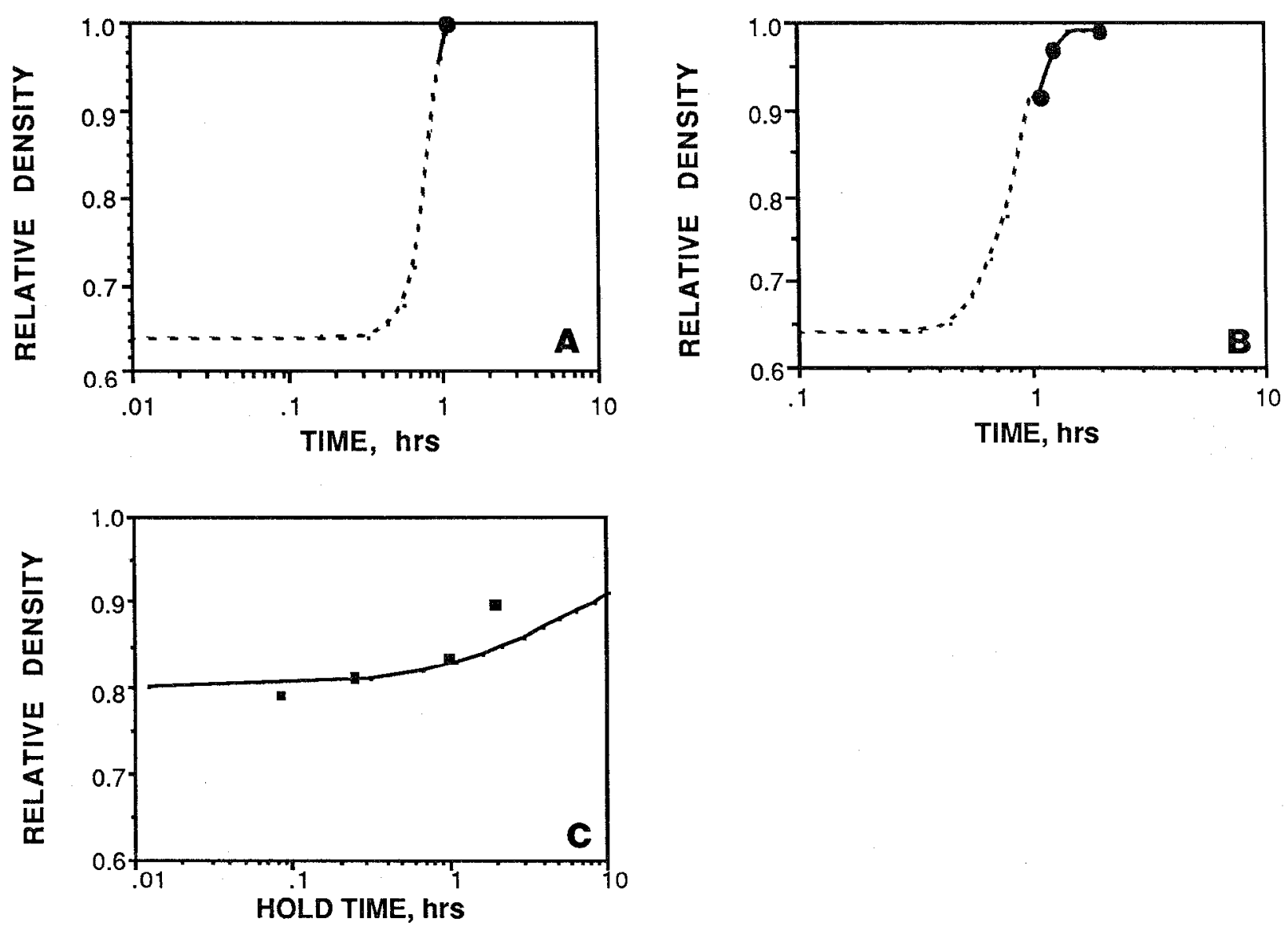

Figure 6. Comparison of densification kinetics predicted by the models (solid lines are densification during the hold time, dashed lines are densification during the ramp-up time) and experimental HIP data at a) $1121^{\circ} \mathrm{C}$ and $100 \mathrm{MPa}$, b) $1121^{\circ} \mathrm{C}$ and $10 \mathrm{MPa}$, and c) $900^{\circ} \mathrm{C}$ and $100 \mathrm{MPa}$.

\section{Discussion and Conclusions}

It must be said that currently the bimodal model is extrinsically bimodal only by consideration of differing powder particle radii. Even incomplete analysis of the HIP densification of a bimodal distribution of powder shows a split as shown on the HIP maps. Future work could include intrinsic differences in a distribution of powder, that is, the variation of material properties with powder particle radius.

The HIP model has been used to point the way to improved as-HIP superalloy material. Using HIP maps as guides, ramped pressure HIP runs have been done in 
an effort to promote uniform superplastic and creep deformation of superalloy powder particles, with promising results (8).

The model has also been extended to consider densification of superalloys by other techniques, such as CAPTM (Consolidation at Atmospheric Pressure) (13) as well as HIP consolidation of other materials, such as superconducting oxide ceramics (15), as shown in Figure 7, and particulate composites (16). The model could also be used to predict closure of pores in castings by HIP.

Perhaps the major impact of the development of the bimodal HIP model is the ability to predict HIP of composites. The model easily treats HIP of a bimodal mixture of powder material of equal or different diameters. Each equation is summed for both particles, however for each powder, the material parameters are different. The geometry remains the same. For example, for densification by yielding, the densification rate becomes:

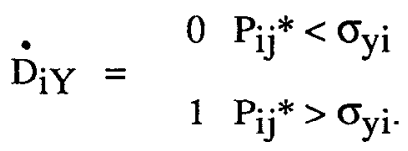

Future work will explore various composite systems.

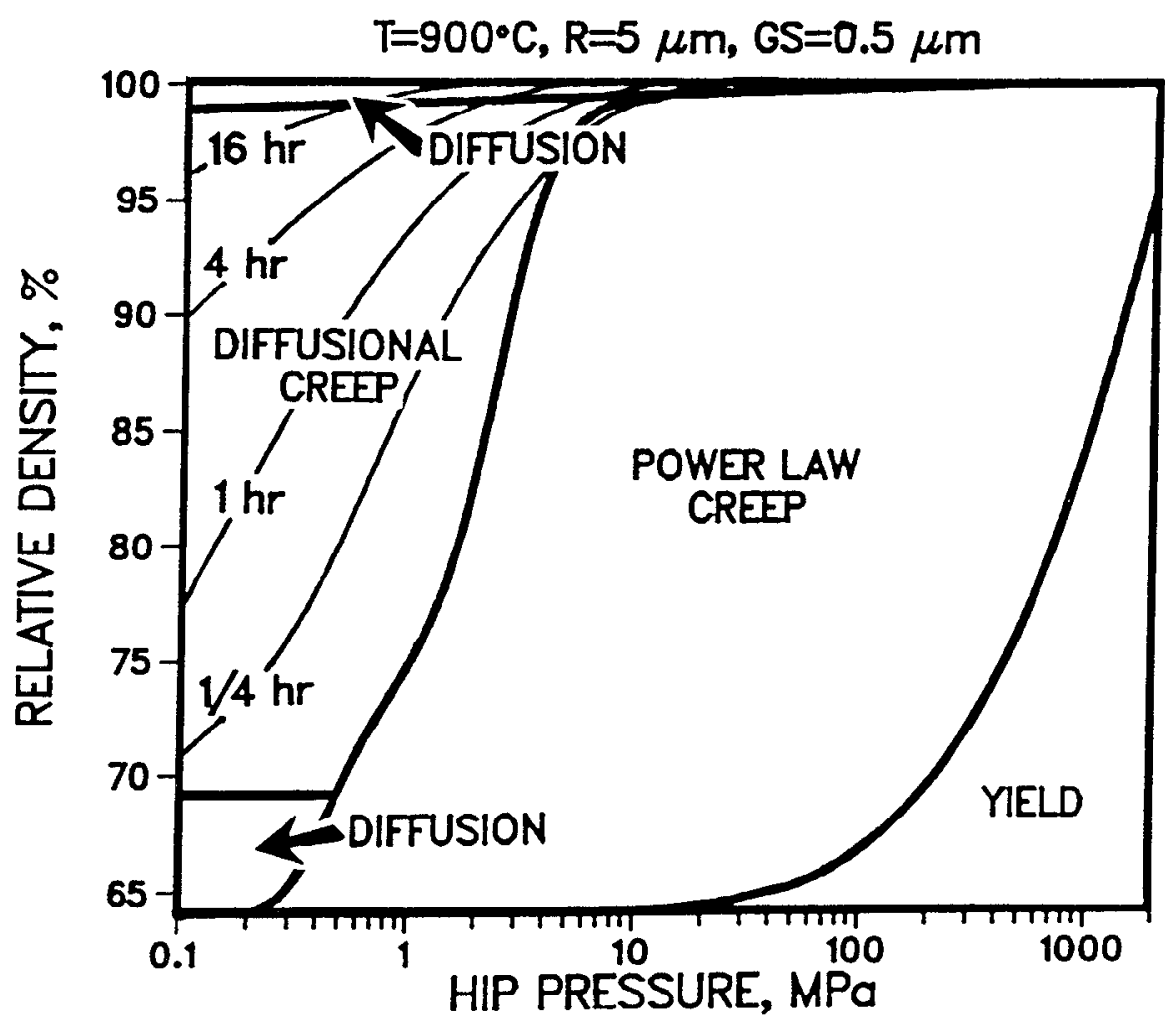

Figure 7. HIP map for monosized powder of the oxide superconductor $\mathrm{YBa}_{2} \mathrm{Cu}_{3} \mathrm{O}_{7-\mathrm{x}}$ at $900^{\circ} \mathrm{C}$, with isochronal lines showing the density achieved at any HIP pressure in a given amount of time.

\section{Acknowledgements}

The authors thank the United States Air Force Office of Scientific Research for sponsoring this research under grant AFOSR-82-0352 monitored by Alan $H$. Rosenstein, and Special Metals Corporation and Wyman-Gordon Company for supplying and processing the materials used in this work. 


\section{References}

1. E. Arzt, M.F. Ashby, and K.E. Easterling, "Practical Applications of HIP Diagrams: Four Case Studies," Metall. Trans. A, 14A(2)(1983), 211-221.

2. A.S. Helle, K.E. Easterling, and M.F. Ashby, "HIP Diagrams: New Developments," Acta Metall., 33(12)(1985), 2163-2174.

3. N.G. Ingesten, R. Warren, and L. Winberg, "The Nature and Origin of Previous Particle Boundary Precipitates in P/M Superalloys," High Temperature Alloys for Gas Turbines 1982, eds. R. Brunetaud et al. (Dordrecht, The Netherlands: D. Reidel Publ. Co.,1982).

4. R. Thamburaj, W. Wallace, Y. N. Chin and T.L. Prakash, "Influence of Processing Variables on Prior Particle Boundary Precipitation and Mechanical Behavior in PM Superalloy APK1," Powder Metall., 27(3)(1984), 169-180.

5. C. Aubin, J.H. Davidson, and J.P. Trottier, "The Influence of Powder Particle Surface Composition on the Properties of a Nickel-Based Superalloy Produced by HIP," Superalloys 1980, eds. J.K. Tien et al., Proc. 4th Intl. Symp. on Superalloys, Oct. 1980, Champion, PA (Metals Park, OH: ASM, 1980),345-354.

6. C.E. Shamblen and D.R. Chang, "Effect of Inclusions on LCF Life of HIP Plus Heat Treated Powder Metal René 95," Metall. Trans. B, 16B(12)(1985), 775-784.

7. S.V. Nair and J.K. Tien, "Densification Mechanism Maps for HIP of Unequal Sized Particles," Metall. Trans. A, 18A(1) (1987), 97-107.

8. J.K. Tien and J.C. Borofka, "Bimodal Modeling of HIP of Superalloys", First Intl. Conf. on HIP, Luleå, Sweden, June 1987 (Luleå, Sweden: CENTEK, in press).

9. R.D. Kissinger, S.V. Nair, and J.K. Tien, "Influence of Powder Particle Size Distribution and Pressure on the Kinetics of HIP Consolidation of P/M Superalloy René 95," Superalloys 1984, eds. M. Gell et al., Proc. 5th Intl. Symp. on Superalloys, Oct. 1984, Champion, PA (Warrendale, PA: TMS-AIME, 1984), 285-294.

10.S.V. Nair, B.C. Hendrix, and J.K. Tien, "Obtaining the Radial Distribution of Random Dense Packed Hard Spheres," Acta Metall., 34(8)(1986), 1599-1605.

11. D.R. Chang, D.D. Krueger, and R.A. Sprague, "Superalloy Powder Processing, Properties and Turbine Disk Applications," Superalloys 1984, op. cit., 245-273.

12. T.E. Howson, W.H. Couts, and J.E. Coyne, "High Temperature Deformation Behavior of P/M Rene 95," Superalloys 1984, op. cit., 275-284.

13. R.D. Kissinger, "The Densification of Nickel-Base Superalloy Powders by Hot Isostatic Pressing" (D.E.S. thesis, Columbia University, 1988).

14. F. Cosandey, R.D. Kissinger, and J.K. Tien, "Cooling Rates and Fine Microstructures of RSR and Argon Atomized Superalloy Powders," Rapidly Solidified Amorphous and Crystalline Alloys, eds. B.H. Kear et al. (New York: Elsevier Science Publ. Co., 1982), 173-178.

15. J.K. Tien, J.C. Borofka, B.C. Hendrix, T. Caulfield and S.H. Reichman, "Densification of Oxide Superconductors by Hot Isostatic Pressing," Metall. Trans. A, (to be published).

16. J.C. Borofka and J.K. Tien, "Modeling of Hot Isostatic Pressing of Powder Composites," (to be published). 